Administrative Issues Journal: Connecting Education, Practice, and Research, Winter 2018, Vol. 8, No. 1: 1-15. DOI: 10.5929/2019.1.14.1

\title{
“This doesn't happen here": Child sex trafficking in rural Oklahoma
}

\author{
Denise Blum, Ph.D. \\ Tania Benoiton, Ph.D. \\ Sean Kinder, M.A. \\ Oklahoma State University
}

\begin{abstract}
The sex trafficking of minors is a hard-to-detect and underreported crime. Its insidiousness makes it exceedingly difficult to recognize, and treatment, once a victim is recovered, is long-term and costly. Urban areas are in the spotlight when it comes to the trafficking of minors. However, the unsuspecting rural context consists of specific dynamics that may make children in the countryside more vulnerable than in the city. Using the case of an Oklahoma town, the researchers conducted a presentation on child sex trafficking for school personnel at a K-8 rural school. They administered pre-and post-surveys and conducted follow-up interviews with a few of the school staff. Findings indicate that several factors influence the persistence of sex trafficking in rural areas, some of which are geographically specific, such as tight small-town networks and a lack of victim services. Another finding was that Oklahoma and other rural states lack comprehensive sex education, which leaves children more vulnerable to sexual predators. Anthony Down's theory of rational ignorance and Bryan Caplan's rational irrationality help explain the cost-benefit ratio that works to maintain the lack of comprehensive sex education and professional training on this issue. The researchers recommend a campaign to promote the benefits of comprehensive sex education while emphasizing the vulnerability of children's safety without it, showing the ties between drug use, gangs, and sex trafficking.
\end{abstract}

Keywords: Educational Policy, Sex Trafficking, Rural, Qualitative

assing endless green farming pastures dotted with oil and natural gas wells, we arrived at a small town in the heart of a rural community with no stoplights and very little industry. Middle school teachers trickled into the classroom after a full day of teaching. Greetings were exchanged with head nods and cordial smiles as they seated themselves in a classroom reserved for our presentation on child sex trafficking and the school. Our objective was to raise awareness through dialogue with the school personnel, leading to further education and implementation of relevant policy and practices.

Through this professional development with school personnel at Scandrick Grade School (pseudonym), this study highlights the challenges that rural areas in general, and Oklahoma in particular, may face in safeguarding their communities against sex trafficking of minors and recommendations for rural school districts regarding proper education on this issue. This study proposes to contribute to a better understanding of the dynamics that make rural communities vulnerable as well as rural dynamics that need to be considered in our education efforts.

\section{Human trafficking}

BLUM, BENOITON, \& KINDER / DOI: 10.5929/2019.1.14.1 
Logan, Walker, and Hunt (2009) defined human trafficking as "the recruitment, harboring, transportation, provision or obtaining of a person for labor or services through the use of force, fraud, or coercion" (p. 8). Human trafficking, which includes sex trafficking, is one of the most underreported crimes today, making statistics very difficult to solidify. Poverty, globalization, and migration are frequently associated with human trafficking, with women and girls being particularly vulnerable. George, Vindhya, and Ray (2010) stated that "gendered migration flows are accompanied by increasing coercion and exploitation of women's bodies and the movement of women's bodies -with or without their consent" (p. 68). Research indicates that gender-based violence continues to be on the increase (Devries et al. 2013; Watts \& Zimmerman, 2002). Ongoing violence is a manifestation of the power inequality and unequal status of women, which only furthers their vulnerability and leads to an increase in the level of violence perpetrated against women (Devries et al. 2013; Watts \& Zimmerman, 2002). The United States "ranks as the world's second largest destination/market country (after Germany) for women and children trafficked for purposes of sexual exploitation in the sex industry" (Schauer \& Wheaton, 2006, p. 146).

Children are especially vulnerable to trafficking due to their age (United Nations Office of Drugs and Crime, 2008). As minors, children typically lack knowledge, understanding, and experience regarding proper sexual relationships and their brains are not fully developed, making underage young people the prime target for "grooming" by pimps. In most cases, the average age of the exploited victim is between 12 and 14 years old (Polaris, 2016). Sex traffickers tend to recruit children because they are not only more unsuspecting than adults, but there is also a high demand for young victims.

Child trafficking is a pervasive global issue that is a rapidly growing "criminal enterprise" (Equality Now, 2013). Equality Now (2013) reported that approximately 2 million kids were involved in child trafficking, worldwide, with $60 \%$ of the cases directly related to sexual exploitation, of which $98 \%$ are trafficked women and girls. Once a victim, a child's physical development can be stunted; due to socialized attachment and typical trauma bonding, the child's developmental and social difficulties may make him or her more susceptible to revictimization (United Nations Office of Drugs and Crime, 2008).

The behavior of trafficking victims can be difficult for third parties to understand. Victims often find it difficult to comprehend what has happened to them, not to mention discussing or explaining it to others. Victims may appear to be uncooperative, detached, irritable, hostile, aggressive, or ungrateful. The stigma attached to children as victims has been shown to have a significant and ongoing impact on their lives, including the possibility of rejection by family and/or community. Due to PTSD and other social, psychological, physical, and emotional complications, the long-term recovery of a trafficked victim is complex, as the sex-trafficked victim's life expectancy is greatly reduced, with approximately $40 \%$ of those recovered surviving past the seven-year mark (Human Trafficking Center, 2016). As revictimization is not uncommon and is often a further consequence of the experience of commercial sex trafficking, this can make treatment both lengthy and challenging (Muftić \& Finn, 2013).

Commercial sexual exploitation of minors takes place in a variety of forms. Aside from the stereotypical pimp-prostitute relationship, these relationships are frequently initiated online with the child describing the treatment as being made to feel "special" and "loved." Child victims may be lured into activities such as modeling, stripping, chat sessions, and pornography.

In the United States, statistics for minors are startling. $19.4 \%$ of homeless youth have been the victims of human trafficking $-15 \%$ trafficked for sex, $7.4 \%$ trafficked for labor, and $3 \%$ trafficked for both (Ryan, 2017). Researchers have also reported that nearly $34 \%$ of lesbian, gay, bisexual, transgender, and questioning (LGBTQ) homeless youth had survived human trafficking; in comparison to $7 \%$ of the general population (Ryan, 2017). 27\% of LGBTQ youth, more than one in four, had been trafficked for sex (Ryan,

BLUM, BENOITON, \& KINDER / DOI: 10.5929/2019.1.14.1 
2017). LGBTQ youth are without safe shelter and social supports and are at a higher risk of trafficking and exploitation (True Colors Fund, 2016). While anyone can be a victim, young people who are homeless or runaways, LGBTQ, African American or Latino, and youth interacting with the child welfare system are more vulnerable to commercial sex exploitation.

The adolescent years are a precarious time for teenagers who are on the cusp of emotional and physical maturity, seeking adult figures outside of their family, as they begin to explore their own identity (Lesser \& Pope, 2010). Greenberger, Chen, and Beam (1998) found that nonparental adults, as well as parents, can have a strong influence on young people's behavior if they consider the adult to be a significant person in their lives. In fact, the young teenager's "trusting and uninformed nature" (Graciela, 2014, p. 4) increases his or her vulnerability to social challenges, including sexual-based violence.

Exposure to violence, such as sexual abuse in the home or bullying at school, can make that individual susceptible to victimization in other contexts (Faris \& Felmlee, 2011; Malik, Sorenson, \& Aneshensel, 1997). Understanding the nexus between sexual violence and human trafficking is crucial, considering the existence of child sexual abuse.

\section{The Vulnerability of Rural Areas}

Most literature regarding child sex trafficking does not distinguish between urban and rural areas. Due to fewer economic opportunities, rural communities tend to reflect people with lower income levels and economic hardship making the community's children more vulnerable to traffickers (Perkins \& Ruiz, 2016). In rural areas, as across the country, successful investigations and prosecutions against traffickers are rare and they know this. Yet, $72 \%$ of the land in the United States is comprised of rural counties (United States Department of Agriculture, 2017), reflecting the need for more research in this area.

The geographic isolation of rural communities is an attractive feature for traffickers, as it helps keep them from having their victims escape or having their operation discovered (Occhiboi, 2015). When the distance to a nearby city separates the victim from needed services, the relatively long distance to a city contributes not only to the victim's difficulty in securing a safe haven, but also a delay in intervention and the lack of local support services. The victim is literally at the trafficker's mercy. In a context without public transportation, it is difficult for victims to remove themselves from the situation and find help. Even if the victim runs, the trafficker will more than likely be able to locate him or her (Occhiboi, 2015). Truck stops are common in rural areas, such as Scandrick, and these stops are all too often sites for trafficking and commercial sexual exploitation.

Rural communities are known for having overlapping and tight networks that can lead to a lack of crime reporting due to close business and family ties or perhaps the perpetrator being a prominent town official (Occhiboi, 2015). Victims are commonly too terrified of their captors, too embarrassed about the crimes they have been forced to commit, or too suspicious of law enforcement to cooperate with investigations. In addition, due to a small population and a small geographical area, the victim may not be able to avoid contact with the perpetrator. The perpetrator may reside in the community after the case is reported, magnifying the victim's sense and reality of being unsafe. When reporting means having to name someone as the trafficker in a close-knit community, the perpetrator frequently is released, and charges dropped or charged with a lesser crime, leaving the victim and the community at risk (Occhiboi, 2015). Furthermore, first responders (police, teachers, and medical personnel) lack specific training or education on trafficking to know the subtle signs, the questions to ask, as well as, the likelihood that victims will deny their victim status.

Although no community is immune from the impact of sexually-based violence, teens from rural school

BLUM, BENOITON, \& KINDER / DOI: 10.5929/2019.1.14.1 
districts have a higher susceptibility to dating violence, especially female students when compared to their urban and suburban counterparts (Spencer \& Bryant, 2000). These precarious conditions in the rural context can lead to sexual behaviors that enhance vulnerabilities related to child trafficking.

The existing literature in rural areas mentions intervention strategies for American Indian Girls in Minnesota (Pierce, 2012). However, the bulk of the literature focuses on cases of sexual assault of minors and current policies when it comes to safeguarding victims (Brade, 2007; Hennessey, 2017; Shewchuk, $2014,2017)$. Curriculum by local advocacy groups, such as Unlock Freedom, continues to grow in its reach; however, its scope is limited in terms of curriculum for the rural context, which is further confirmed by the absence of literature about the rural context and trafficking.

\section{Context: Scandrick Community and School Site}

In the countryside, Scandrick, Oklahoma lies between a major turnpike and a highway, which brings commercial trucks and other traffic into the area. Scandrick has one oil and water tank constructing business that opens the town to a variety of trucking activity.

Both youth and middle-aged adults spend time around the town's one mini-mart. Many of the homes are in disrepair. Those parents with employment have to travel outside of the area to work in jobs requiring little schooling. A handful of parents have jobs in the oil and gas arena and/or are farming families. The town used to have two police officers; however, only one remains after the other was arrested for racketeering. Scandrick is known for substance abuse, primarily methamphetamine, marijuana and alcohol. According to Perkins and Ruiz (2016), children of parents who have substance addictions are more vulnerable to substance abuse or even becoming recruited into trafficking to escape their circumstances.

Scandrick Public Schools (SPS) is a PreK-8 district. The school's campus consists of one elementary (PreK4) building and one middle school (5-8) building that are positioned between a fire station, a gymnasium and a football field. The elementary and middle school are made up of approximately 200 students, 16 certified teachers, and two administrators, with one principal and one superintendent for both buildings. The community has a $19 \%$ poverty rate, with $38 \%$ being single-parent families and $77.5 \%$ of the children receiving free or reduced lunches. The school demographics reflect the community with $81.0 \%$ White, 13.0\% Native American, 2\% African American, 1\% Hispanic American, and 1\% multiracial. The percentage of Special Education students is $20.6 \%$ (source is not provided to protect the anonymity of location).

\section{Researchers}

Two of the researchers are graduate students in an educational leadership Ph.D. program. The other researcher is a professor in the social foundation's program in the same college of education. One of the graduate students is from rural Oklahoma; he held an internship assisting the principal and superintendent at Scandrick Public School at the time of the study and spoke to Principal Zandy (pseudonym) about doing a professional development session about child sex trafficking. The other researcher is an international graduate student from a rural area in her country. The instructor of the course was the third researcher and mentored the graduate students throughout the research process and had a major role in writing up the research. The presentation was a course requirement for the graduate course, Child Sex Trafficking and Schools, in which all students were trained and received certification to conduct the presentations.

Principal Zandy thought that the one-hour presentation would be a great professional development topic for their weekly "After-School Power Chat" meetings in March of 2016. In addition, Principal Zandy

BLUM, BENOITON, \& KINDER / DOI: 10.5929/2019.1.14.1 
authorized us to solicit school personnel to participate in both pre- and post-surveys, as well as follow-up interviews. The two graduate student researchers co-presented the Unlock Freedom curriculum to the school staff. Both shared in all processes equally: presentation of curriculum, administration, and analysis of surveys, and conducting interviews.

\section{Methodology}

Using a mixed methods approach, we employed a pragmatic research design and an interpretivist perspective that included both qualitative and quantitative approaches. Our pragmatic research approach combined both positivist and interpretivist positions within the scope of our research study to respond to our research questions:

1. What knowledge and experiences do rural Oklahoma school personnel have regarding child trafficking?

a. What challenges do rural contexts face regarding child trafficking?

b. What challenges do rural contexts face in educating the students and the community?

2. What are recommendations for providing more knowledge and safety to rural areas regarding sex trafficking?

The rationale for the design was to capture both prior knowledge and experiences, as well as the perspectives of faculty and administration on human trafficking in their rural school context and to examine what new knowledge, if any, was gained from the presentation.

All fourteen Scandrick school personnel were invited, via email, to participate in an online fifteen-question multiple-choice and Likert-scale survey to assess prior knowledge on the human trafficking of minors. Eleven participants took the pre-survey. After the researchers' presentation, those who attended received a follow-up, online post-survey with the same questions to document newly acquired knowledge. Only four participants completed the post-survey. As a result of a small sample for the preand post-surveys, the surveys were analyzed using basic descriptive statistics.

We solicited volunteers from those who attended the presentation for the follow-up interviews. We had four school personnel-three educators and one administrator volunteer. The interviews provided an opportunity to explore the school personnel's knowledge, experiences, challenges, and recommendations regarding child sex trafficking in Scandrick. We utilized purposeful sampling and a case study approach (Yin, 2017) with teachers and administrators as a source of "information-rich cases for study in depth" (Patton, 2002, p. 230). To achieve triangulation, we drew data from multiple sources: pre- and postsurveys, observations during the presentation, one-on-one interviews, and Oklahoma policies related to sex education. In analyzing the data, we used an inductive approach, reviewing the interview transcriptions multiple times and using open coding to label concepts, define and develop categories (Saldaña, 2016). Data reduction followed, with dominant themes being noted (Jauch, Osborn, \& Martin 1980).

Learning that some of the school personnel had uncertainties and misinformation about sex trafficking in general, and about rural factors more specifically, we evaluated policies that might be influencing the status of sex education in Oklahoma. We analyzed Oklahoma house bills and state policy content with a directed and iterative approach, whereby our analysis started with relevant research findings as guidance for initial codes. As coding progressed, we categorized codes that shared similarities, threading them into our data groups from interviews and observations that logically and intuitively fit together. Working with

BLUM, BENOITON, \& KINDER / DOI: 10.5929/2019.1.14.1 
these categories/groups, we searched for patterns and emerging themes using analytic memo writing. This allowed us to structure the experiences and challenges that might influence related constituents.

\section{Findings}

From the pre-survey, the participants' responses reflected an "above average" knowledge of human trafficking. This was surprising based on the lack of professional development regarding child trafficking. The four who did respond to the post-survey showed a stronger grasp of the concepts surrounding human trafficking as a result of the presentation.

From our observation of the presentation, we noted that some teachers offered their perspective and others asked clarifying questions. The staff realized that the schools were potential feeding grounds for predators and that there was an imminent need to educate on this issue, especially about internet safety. The school personnel were alarmed at the statistics we presented and wanted more information, especially regarding the training Unlock Freedom could provide for their school.

\section{Educating the Community on Trafficking}

The three teachers and the principal were interviewed after the presentation to gain further information. They indicated that conservative community values would hinder school presentations to educate students and their families on trafficking; as sex education is a hot button topic. Comprehensive sex education is not mandated by Oklahoma and there was no sex education in Scandrick grade school at the time of the study. In addition, the administration mentioned that it would be a budgetary issue to incorporate education on human trafficking as a part of professional development for teachers or to finance presentations as part of a school assembly. Rural schools tend to be even more challenged than urban districts when it comes to funding. However, it was important to the community to not remain ignorant. Mrs. Reese reported, "If the kids don't know what's going on...a lot of them are just, they're ignorant, they have no idea, they're promised the world and...have no idea what's gonna happen."

The teachers concurred that educating school children about the dangers of human trafficking should be part of their school experience, especially because schools have been shown to be active recruitment sites. As Mrs. Elliot stated, "The students have to be empowered... They have to know where to seek help, who to talk to, and to know that it's wrong." This instills a solid foundation for adolescents to make informed choices and provides suspected victims with information on relevant services. The staff also suggested creating time and space in the classroom where children can discuss their own lives and the issues they deem important.

The curriculum presentation gave teachers and administrators new insights into student behavior. Mrs. Elliot commented, “It's a sad reality... We've seen the fallout of [trafficking] for years, we just haven't realized that that was why...we were having such trouble." She admitted that the presentation has "made [her] more cautious and it's made me more sympathetic...to students...trying to understand why they may react a certain way or why they may... be in the moods that they are in." Similar thoughts were echoed by Mrs. Eason who stated that the "main goal...is the safety of my students...physical safety...psychological safety." All of the staff expressed concern for student safety.

Although the concern of the school personnel was strong, they were concerned about making a false report. Mrs. Reese stated, "I mean you just can't have hearsay or speculation, you've got to be able to prove it, I mean you report stuff, but it doesn't mean they're going to be taken care of." I could sense her frustration when she said, "I mean they can call the police but again it's still hearsay, you've gotta have

BLUM, BENOITON, \& KINDER / DOI: 10.5929/2019.1.14.1 
some hard evidence." Even Mrs. Elliot expressed similar hesitancy in reporting suspected cases, "because if I'm wrong then I have made a false accusation against a parent or child and I don't want to do that."

While Mrs. Elliot stated that "if [she] did see warning signs of human trafficking in [her] students [her] first duty is to report it to the proper authorities and to school personnel," she admitted that she "didn't know a whole lot, just that kind of perception.... I now know that it's [being a minor which makes one too young to consent to prostitution/sex trafficking] up until 18...but I guess after 18, you're free to make choices on your own." Yet, Mrs. Elliot did not want to make a mistake, not realizing that the Department of Human Services does not see any call as wasted even if it turns out to be in error.

All of the school personnel talked about acquiring a new level of awareness as a result of our presentation. They realized that human trafficking could happen anywhere and not to just with children from troubled families. Mrs. Gill commented that this new knowledge made her "become more aware." Afterward, when she heard about it on the news, she said that she "stopped to listen to what was going on." Mrs. Gill admitted that she had become "a lot...wiser...because before then [the presentation] I really...just wasn't aware you know...." The school principal was pleased with our presentation to the school staff. He stated that it "opened a lot of our teachers' eyes on what's going on," and that "it's something [that they'II] definitely continue to be in dialogue with one another about." It also furthered conversations between school personnel "on what we need to do to protect our students in that area."

With the use of social media and peer networks, Mrs. Reese stated that human trafficking is "coming more and more into the kids in the ages [middle school ages] that we see every day that we were not aware of before." Mrs. Eason calmly stated that "[they knew] that one of [their] students was trafficked before she was placed in foster care because her foster mother shared that with me." She continued, stating that "[she] suspected that one of [her] male students has possibly been...simply because of some behavior and some things that he has said." As a direct witness to this tragedy, Mrs. Eason said, "It's probably more common than we understand." And in a frustrated tone, she commented that this topic is never addressed in teacher education, professional development, or with students in any class.

Mrs. Reese discussed why students might end up as victims of trafficking. She mentioned the allure of having trendy material items, a better life, and the misconstrued belief of being loved by someone: "They might see it as a positive future but in reality, it's harmful." The risk is especially high among, as she noted, "[Those] who would want definitely out of the lifestyle environment that they're raised in." Mrs. Reese pointed out that these students are blinded by false hopes and "...promised opportunities, and they might not be pleasant opportunities, but it gets them out of this town and where they're stuck." Therefore, not only may young people be trying to escape serious family issues, but the rural context may be a factor in their desire to explore a different kind of life that may include travel.

Knowing the indicators is a concrete first step. Principal Zandy stated that, as educators, they are "...trying to be preventative by looking for kids that may be in that situation, identifying the warning signs so that we can address those issues as they come up." Nevertheless, he seemed to believe that Scandrick did not have this problem: "I don't think it's...I mean it hasn't hit [Scandrick school district] that I know..." And then immediately stated, "I know there are things going on outside our control.... I know there's lots of molestation that leads to other things, but I don't think it's as big an issue here than in bigger cities where there's more opportunities." While there was basic awareness on the issue of human trafficking, he stated, "The biggest thing is bringing awareness to the topic that we don't typically deal with here, but at any point could deal with." This last comment also reinforces the common perception that "this doesn't happen here," when, in fact, it is suspected that there is no school that isn't experiencing at least one child

BLUM, BENOITON, \& KINDER / DOI: 10.5929/2019.1.14.1 
who is being trafficked. Zandy's commentary shows a break in the link between potential identifiers of abuse and the potential for trafficking in rural areas, despite clear evidence showing otherwise.

The interview with the superintendent revealed that careful screening needs to be exercised in hiring adults who work with children in the school. Superintendent Willis spoke to one of the researchers about how teacher shortages lead to more flexibility in the hiring process, which led him to hire a teacher who is a registered sex offender. He swished his teeth with his Pepsi, leaned back in his broken chair, and explained that they felt comfortable with the hire because "it wouldn't be too hard to keep an eye on the teacher."

\section{Oklahoma Policy on Comprehensive Sex Education}

With an interest in incorporating education on trafficking in the school curriculum, the researchers came across possible policy challenges, some of which have left children ignorant of both healthy and unhealthy relationships, as well as the biological basics of sexual reproduction. Oklahoma has no state mandates on comprehensive sex education. As it stands, Oklahoma holds an "abstinence-only-until-marriage" policy on sex education with HIV/AIDS education. Meanwhile, the state has the second highest teenage pregnancy rate in the nation (Oklahoma Policy Institute, 2016). In addition, with the passage of House Bill 2797 in 2016, a special revolving fund was created that was earmarked only for materials that promote the "humanity of the unborn" and oppose abortion. The bill specifically requires that those messages become part of high school instruction (Krehbiel, 2016). Democrat Representative, Jason Dunnington took issue with the bill's specific prohibition on using any of the new fund's money for curriculum on human sexuality. He is reported to have said, "I hear you say this has nothing to do with sex education... But children who are in the womb are there because people have sex. It doesn't make sense not to include that" (Krehbiel, 2016). This bill requires that the Oklahoma Department of Health develop informational material "for the purpose of achieving an abortion-free society" (Krehbiel, 2016). This creates an odd tension with no state law mandating that students receive sex education while mandating anti-abortion curriculum.

The need for comprehensive sex education is critical. As of 2017, Oklahoma is experiencing an unprecedented outbreak of syphilis due to widespread drug use and addiction, especially methamphetamine. Portia King, a veteran Oklahoma state health investigator stated, "Drugs like meth really ramp up someone's sexual appetite, and so they tend to have a lot of partners... They have a lot of partners within their drug network, and so it's a lot of people sharing the same partner" (May, 2017). In 2017, in an Oklahoma juvenile detention center, two girls and one boy reportedly had syphilis; the youngest was 14 . This discovery came after seven years of testing for it and not having a single case. The teenagers did not know each other, live near each other, or attend the same school (May, 2017). Hoffman (2017) elaborated in his New York Times article: "Then, in February, a prison inmate tested positive. In interviews, he listed 24 sex partners - some his own, others the so-called pass-around girls for gangs, usually in exchange for heroin or methamphetamine." Hoffman continued, "The spread [of STDs] is migrating out of the city" (2017).

This situation pointed the way to a syphilis spread that, by March, led health officials to declare an outbreak-one of the largest in the country. This most recent wave of infections, spread through gang networks and prostitution rings, has made health officials' jobs not only difficult, but also dangerous. In US history, comprehensive education campaigns have shown results, lowering syphilis rates to almost non-existent.

BLUM, BENOITON, \& KINDER / DOI: 10.5929/2019.1.14.1 
The dominant Christian right-wing beliefs of policymakers have also influenced access to knowledge about LGBTQ issues in Oklahoma public schools. House Resolution 1039, by State Rep. Sally Kern, in 2005, called on Oklahoma libraries to "confine homosexually themed books and other age-inappropriate material to areas exclusively for adult access and distribution" (Greenblatt, 2010, p. 253), calling this area the "family talk" section. In addition to LGBTQ-themed books, this section also houses substance abuse literature, in effect, labeling reading material about sex trafficking or LGBT as deviant. The section is named as such because parental discretion and adult accompaniment are expected for a child's access. The policy was amended in 2006, stipulating that the section remain at least five feet from the ground. LGBTQ advocacy groups have fought hard, most recently in 2016, to change these restrictions of access to these books. Keeping information out of reach, especially for LGBTQ youth, is not only stigmatizing and discriminating but also disempowering, which ultimately adds to the vulnerability of this population.

Among the state's five largest districts, the largest, Oklahoma City Public Schools, provides no sexeducation classes to students at any grade level, although the district used to offer a comprehensive program two decades ago. The program was phased out due to a need to spend more time focusing on college preparedness and standardized tests (Forman, 2014). Tulsa, the second largest school district, has partnered with local organizations to teach comprehensive sex education and pregnancy prevention in middle and high schools. In addition, some Tulsa schools and nearby districts have welcomed Unlock Freedom curriculum into their classrooms to raise awareness among the student body about human trafficking.

Research has shown that where schools offer comprehensive sex education, the outcome is that student knowledge about sex education issues is generally high (Allen, 2005). Oklahoma's reluctance to have a more comprehensive sex education approach is a reflection of "this doesn't happen here," and the failure to recognize the link between sex education and trafficking. Noteworthy is the fact that, annually, legislation is introduced to allow comprehensive sex education into Oklahoma schools and the bill continually fails to make it out of committee.

\section{Discussion}

Sex education is an important link to combatting sex trafficking. The more that young people become aware of what is sexually healthy or unhealthy, as well as pimps' manipulative tactics, and victim services, the more empowered youth can become to combat predators. However, sex education is a topic of competing for political interests among parents/caregivers, teachers, school management, educational policymakers, civil liberties organizations, conservative and liberal groups. Oklahoma has a strong commitment to "conservative" approaches regarding sex education. In the face of a serious commitment to abstinence-only, anti-abortion, and HIV/AIDS education, programs that take any other approach are costly. So much so that any (supposed) benefits would not outweigh them.

Legislature and representatives propose and evaluate policy considering economic, political and social costs of education and knowledge acquisition. Could it be that our representatives see that mandating comprehensive sex education might cost more-financially, psychologically, or materially-than the benefits that such information will confer? Is remaining ignorant rational in order to protect certain interests? Anthony Downs (1957) introduced the economic theory of rational ignorance, claiming people will seldom educate themselves on a specific issue unless the perceived benefit of said education clearly outweighs the cost of their embraced beliefs. People may be informed, but one of two things is occurring; they understand that the cost of embracing the facts is so high that they would be better off either a) simply ignoring those facts, or b) actively denying those facts. In either case, they make a choice either to discount, or somehow contextualize that information, or not to use it at all.

BLUM, BENOITON, \& KINDER / DOI: 10.5929/2019.1.14.1 
The personal costs to them of discounting, denying, or not subscribing to the idea are rarely overwhelming; it is usually much easier to guess or go with heresy than to read up on relevant research or to review and analyze one's existing understanding. A clear example is the teaching of anti-abortion ideology in a classroom setting while also censoring the basics of reproduction. In other words, endorsing one view without giving any time to the other side of the formula. Rational ignorance may be the reason that some Oklahoma stakeholders advocate for very limited sex education.

Bryan Caplan (2001), another economist, has proposed the concept of rational irrationality to reconcile the widespread existence of irrational behavior, particularly in the realms of religion and politics, with the assumption that rationality is created by mainstream economics. Caplan (2001) stated that when people have a propensity towards irrationality, or what goes against typical rational behavior, they find it more efficient to dispense with logical reasoning in exchange for more satisfying beliefs. As such, people may deviate from rational expectations, because they have a specific alternative view or belief they think/prefer as true, called a "bliss belief." For example, based on a bliss belief that one should abstain from sex until married, sex education should not be taught in school for fear that more information might increase sexual activity and teen pregnancy among youth, even though research (Allen, 2005) has demonstrated the contrary. Within the context of the person's belief system, he or she is acting rationally. It's only relative to typical understandings of rational behavior that the person's preferential order becomes problematic.

Rational irrationality and rational ignorance share some key similarities in that both theories reject the claim that people may be rational. In addition, Caplan purported that people who operate on rational irrationality believe that their bliss belief is true and rational; it is sustained by the person adjusting his or her "level of intellectual self-discipline and emotionalism to match the practical import of the questions" $(2001$, p.9) he or she faces. The theory of rational irrationality, like the theory of rational ignorance, predicts that when the personal costs are low, that people will gather little information or buy in to a different proposal. But, unlike the rationally ignorant, the rationally irrational nevertheless form definite conclusions. They know what they want the truth to be, and if the error is cheap, then they choose their bliss belief even if the information they have is at odds with data-driven research. When personal costs are low, one can expect conclusions that may not be reasonable. Perhaps then rational irrationality influences Oklahoma's sex education policy to be a very limited one, using a heteronormative framework and confining sex education to anti-abortion and abstinence-only-until-marriage to honor one's bliss belief.

Oklahoma's techno-rational approach to sex education (Sears, 1992) focuses on the technical or physiological aspects of sexuality, such as prevention of sexually transmissible infections and unplanned pregnancy. In this way, official school culture tends to educate young people as if their identities were non-sexual (Allen, 2007), leaving them without knowledge of support services as they experience dating, as well as being exposed to unhealthy situations such as sexual predators, sexual abuse, and possible peer recruitment into gangs and trafficking.

Perhaps it is both the rational ignorance of perceiving the costs (economic, social, and psychological) as outweighing the imperfect nature of the status quo, as well as the rational irrationality of confronting deeply embedded belief systems that prevent change. The only way to change the status quo is to change the perceived cost-benefit ratio. This cannot be done simply with more or better information. Rational ignorance is a purposeful ignorance.

Getting voters to buy into the cost-benefit ratio is critical. How can we achieve this considering rational ignorance and rational irrationality form the foundation of the inertia that bars the proposal for

BLUM, BENOITON, \& KINDER / DOI: 10.5929/2019.1.14.1 
comprehensive sex education from going beyond committee in the legislature? We propose education campaigns that underscore the vulnerability and potential for the victimization of "young, innocent children," and the widespread nature of sex trafficking, which means "it could happen to your kid, too." Creating these kinds of changes of approach do change the cost-benefit ratios and, therefore, could move the needle forward somewhat, even if not in an ideal way. Additional cost benefits to comprehensive sex education could be emphasized as well, including a reduction in teen birth rates (Forman, 2014; Kholer, Manhart, \& Lafferty, 2008) without increased sexual activity or sexually transmitted diseases (Kholer et al., 2008). Social services are scarcer in rural areas, and, as a rural state, Oklahoma policymakers need to consider comprehensive sex education as a vital tool for diminishing criminal activity, such as sexual abuse and trafficking, and empowering our youth to know how prevalent trafficking is and the manipulative techniques that might be used, to identify and protect themselves from perpetrators, to report crime and other suspicious activity, and know how to access services. Collaboration among all stakeholders is necessary to protect children. Policymakers and voters must consider the cost of a child's life, when not voting in favor of comprehensive sex education.

\section{Recommendations}

Teacher training and professional development must extend beyond curriculum development and classroom management to include skills for identifying sexual abuse, trafficking, and internet safety. The covert nature of human trafficking makes it even more challenging to identify and assist potential victims (McClain \& Garrity, 2011). Hence, comprehensive training is recommended for professionals who are most likely to engage with potential victims: social workers, doctors and other health care professionals, law enforcement, and even school personnel. Being able to critically "read" the school context is imperative in taking steps toward protecting young people. Principal Zandy agreed that ongoing training should be a part of every school district's preventative measures where "discussion and dialogue about the signs and symptoms of what you're looking for, and training the kids has...to play a role."

Comprehensive sex education should be mandated in schools. The lack of formal sex education in the schools draws well-informed predators to the area. With a child's average lifespan of no more than seven years after recruitment, it is time to mandate comprehensive sex education throughout the state. It is imperative that legislators, school personnel, and parents start to recognize trafficker's manipulative techniques, especially with social media.

Prohibit the hiring of sex offenders in the school context. School policy should prevent sex offenders from being hired to work in schools, as teachers, administrators, staff, or otherwise.

We advocate for systematic statewide professional development for educators on trafficking. This short curriculum presentation succeeded in raising awareness among school personnel. Principal Zandy remarked, "It was eye-opening for them." It is proof that extensive training will provide a better and deeper understanding of issues related to trafficking and internet safety and enhance the capacity for school personnel to identify the symptoms and signs of a suspected victim of human trafficking. In addition, school professionals will be better prepared to assist and guide the suspected victim to access services and resources that will provide the security and protection they deserve. Identifying victims and predators is essential to countering this pervasive crime. These skills can be a lifeline for potential victims of human trafficking.

\section{Conclusion}

Oklahoma is a major supplier of underage victims involved in sex trafficking; our geographical location in the Midwest and access to interstate highways make our state an at-risk environment. Teachers need

BLUM, BENOITON, \& KINDER / DOI: 10.5929/2019.1.14.1 
adequate training and resources in order to identify and access services that will provide our children the protection they deserve, regardless of budgetary concerns. This research is a call to action for all stakeholders in education. With the use of the internet and school sites for the recruitment of minors into sex, there is a great need for education in the schools and with those who work with minors. Teachers care about their students, and we need to show that we are listening to them and care about the future generations. It is not enough for people to come together in dialogue in order to gain knowledge of their social reality. They must act together upon their environment in order to critically reflect upon their reality and transform it through further action and critical reflection. The benefits will outweigh the costs.

Scandrick public school district provided the opportunity to observe how system actors, primarily administrators, approach the issue of child trafficking in their district. The findings showed how school personnel perceived the potential for trafficking of minors in Scandrick and what security and reporting procedures the district had in place at the time to protect children. After the one-hour training conducted by us, the administrator was fairly non-committal in providing more teacher training to the school or community on this issue. Additionally, we saw a lack of adequate security measures that protect the physical building and academic environments, such as security cameras, resource officers, visitor badges, etc. Rather, this rural public-school context relies heavily on community and internal stakeholder trust to act as security, which can be problematic as this may not adequately safeguard children, especially when the perpetrator is a community member. Just like most rural areas, the small-town mentality establishes a "fixed" culture based on a tightly spun web of relationships, increasing the likelihood of immutability to change or interrogation.

This Oklahoma case study provides an example of a rural state context, demonstrating that small towns are not immune to child trafficking. School personnel should be trained in trafficking detection, investigation, and response so that school staff understand the unique needs of trafficking victims who are typically in fear of being discovered because of reprisal from their pimps. State laws should provide victims immunity for crimes they were forced to commit while under the control of their traffickers. Addressing human trafficking in rural America is not just about waiting for services in urban areas to expand into rural areas; it is not about replicating successful solutions from the city. Rural trafficking has its own unique characteristics, and the solutions aimed at addressing it must take this into consideration.

\section{References}

Allen, L. (2005). Sexual subjects: Young people, sexuality, and education. Basingstoke: Palgrave.

Allen, L. (2007). Denying the sexual subject: School's regulation of student sexuality. British Educational Research Journal, 33(2): 221-34.

Brade, C. (2007). Have we really come that far: Child welfare legislation in Ontario. Ontario Association of Children's Aid Societies Journal, 51(4), 7-16.

Caplan, B. (2001). Rational ignorance versus rational irrationality. Kyklos, 54(1), 3-26.

Devries, K. M., Mak, J. Y., Garcia-Moreno, C., Petzold, M., Child, J. C., Falder, G., ... Watts, C. H. (2013). The global prevalence of intimate partner violence against women. Science, 340(6140), 15271528.

Downs, A. (1957). An economic theory of political action in a democracy. Journal of Political Economy, 65(2), 135-150.

BLUM, BENOITON, \& KINDER / DOI: 10.5929/2019.1.14.1 
$\begin{array}{lllll}\text { Equality } \quad \text { (2016). } & \text { Resources. } & \text { Retrieved from }\end{array}$ https://www.equalitynow.org/campaigns/trafficking-survivor-stories/resources

Faris, R., \& Felmlee, D. (2011). Status struggles: Network centrality and gender segregation in same-and cross-gender aggression. American Sociological Review, 76(1), 48-73.

Forman, C. (2014). Sex education varies widely in Oklahoma schools: Many don't go beyond the statemandated HIV/AIDS education. Retrieved from http://www.tulsaworld.com/news/education/sex-education-varies-widely-in-oklahomaschools/article 9d114e75-7430-5807-9f1a-8fe5fa02caaa.html

George, A., Vindhya, U., \& Ray, S. (2010). Sex trafficking and sex work: Definitions, debates and dynamics-A review of literature. Economic and Political Weekly, 64-73.

Graciela, R. (2014). A quantitative study: On social workers' awareness in identifying human trafficked victims. Retrieved from csusb.edu.

Greenberger E, Chen, C., \& Beam, M. R. (1998). The role of "very important" nonparental adults in adolescent development. Journal of Youth and Adolescence, 27, 321-343.

Greenblatt, E. (Ed.). (2010). Serving LGBTIQ library and archives users: essays on outreach, service, collections and access. Jefferson, NC: McFarland.

Hennessey, S. (2017). Vulnerable children: Law and policy in Nova Scotia school boards. (Master's thesis). Retrieved from http://ec.msvu.ca:8080/xmlui/bitstream/handle/10587/1805/StephanieHennesseyMASPThesis 2017.pdf? sequence $=1 \&$ isAllowed $=y$

Hoffman, J. (August 24, 2017). Hunting a Killer: Sex, Drugs and the Return of Syphilis. Retrieved from https://www.nytimes.com/2017/08/24/health/syphilis-std-united-states.html? $r=0$

Human Trafficking Center. (2016). Retrieved from http://humantraffickingcenter.org

Jauch, L. R., Osborn, R. N., \& Martin, T. N. (1980). Structured content analysis of cases: A complementary method for organized research. Academy of Management Review, 5(4), 517-525. Retrieved from http://www.jstor.org/stable/257457.

Krehbiel, R. (March 2, 2016). State House approves anti-abortion school curriculum bill. Tulsa World. Retrieved from http://www.tulsaworld.com/news/government/state-house-approves-antiabortion-school-curriculum-bill/article 4e8cbcfb-cc8b-52fc-bd1b-90a9e85a8353.html

Lesser, J. G., \& Pope, D. S. (2010). Human behavior and the social environment: Theory and practice--(2 ${ }^{\text {nd }}$ Ed.). New York: Allyn \& Bacon.

Logan, T. K., Walker, R., \& Hunt, G. (2009). Understanding human trafficking in the United States. Trauma, Violence, \& Abuse, 10(1), 3-30.

Malik, S., Sorenson, S. B., \& Aneshensel, C. S. (1997). Community and dating violence among adolescents: Perpetration and victimization. Journal of adolescent health, 21(5), 291-302.

May, C. (September 2, 2017). Meth addiction and sex trafficking are fueling Oklahoma's growing syphilis outbreak. Salon. Retrieved from http://www.salon.com/2017/09/02/meth-addiction-and-sextrafficking-are-fueling-oklahomas-growing-syphilis-outbreak/ 
McClain, N. M., \& Garrity, S. E. (2011). Sex trafficking and the exploitation of adolescents. Journal of Obstetric, Gynecologic, \& Neonatal Nursing, 40(2), 243-252.

Muftić, L. R., \& Finn, M. A. (2013). Health outcomes among women trafficked for sex in the United States: a closer look. Journal of interpersonal violence, 28(9), 1859-1885.

Occhiboi, A. (2015). Trafficking in rural America. Retrieved from https://love146.org/trafficking-in-rural-america/

Oklahoma Policy Institute. (2016). Oklahoma's teen birth rate is near the highest in the country. We can do better. Retrieved from http://okpolicy.org/oklahomas-teen-birth-rate-near-highest-countrycan-better/

Patton, M. Q. (2002). Qualitative research \& evaluation method. Thousand Oaks, CA: Sage Publication, Inc.

Perkins, E. B., \& Ruiz, C. (2017). Domestic minor sex trafficking in a rural state: Interviews with adjudicated female juveniles. Child and Adolescent Social Work Journal, 34(2), 171-180.

Pierce, A. (2012). Shattered hearts: The commercial sexual exploitation of American Indian women and girls in Minnesota. Minneapolis: Minnesota Indian Women's Resource Center.

Polaris. (2016). Retrieved from https://polarisproject.org

Ryan, K. M. (April 17, 2017). One in five homeless youth trafficked, new research reveals. Huffington Post. $\quad$ Retrieved from http://www.huffingtonpost.com/entry/one-in-five-homeless-youthtrafficked-new-research us 58f5032ee4b015669722517d

Schauer, E. J., \& Wheaton, E. M. (2006). Sex trafficking into the United States: A literature review. Criminal Justice Review, 31(2), 146-169.

Sears, J. (Ed.). (1992). sexuality and the curriculum: The politics and practices of sexuality education. New York: Teachers College Press.

Shewchuk, S. (2014). Children in need of protection: Reporting policies in Ontario school boards. Canadian Journal of Educational Administration and Policy, 162, 1-37.

Shewchuk, S. (2017). Children in need of protection: Reporting policies in British Columbia school boards. Canadian Journal of Educational Administration and Policy, 177, 1-41.

Spencer, G. A., \& Bryant, S. A. (2000). Dating violence: A comparison of rural, suburban, and urban teens. Journal of Adolescent Health, 27(5), 302-305.

United Nations Office on Drugs and Crime. (2008). Toolkit to combat trafficking persons. United Nations Publications. Retrieved from https://www.unodc.org/unodc/en/humantrafficking/2008/electronic-toolkit/electronic-toolkit-to-combat-trafficking-in-persons--index.html\#Top

Watts, C., \& Zimmerman, C. (2002). Violence against women: global scope and magnitude. The Lancet, 359(9313), 1232-1237.

Yin, R. K. (2017). Case study research and applications: Design and methods. Los Angeles, CA: Sage publications. 


\section{About the Author}

Denise Blum (d.blum@okstate.edu) is an Associate Professor at Oklahoma State University in Social Foundations. She is a member of the Tulsa Task Force on Human Trafficking and teaches a course on Human Trafficking.

Tania Benoiton (tania.benoiton@okstate.edu) has her Ph.D. in Educational Leadership and Policy Studies. Her research focuses on teacher and student leadership in K-12 settings.

Sean Kinder (sean.kinder@okstate.edu) is a Graduate Research and Teaching Assistant at Oklahoma State University pursuing a Ph.D. in Educational Leadership and Policy Studies. His research interests focus on educational leadership and policy in K-12 public school contexts. 